\title{
Self-reported Anxiety and Coping: A Cross-Sectional Study among Saudi Nursing Students during COVID-19 Pandemic using GAD-7 and Briefcope
}

\author{
Mohammed Asad', Atallah Alenezi', Mohammed Nasser Alsalowly ${ }^{1}$, Syed Mohammed Basheeruddin \\ Asdaq ${ }^{2, *}$, Abdulhakeem S Alamri3,4, Walaa F Alsanie ${ }^{3,4}$, Majid Alhomrani ${ }^{3,4}$, Yahya Mohzari ${ }^{5}$, Ahmed \\ Alrashed ${ }^{6}$, Ibraheem N Shammakhi ${ }^{7}$, Muath F Almutairi ${ }^{7}$, Norah N Aldhawyan ${ }^{7}$, Mansour A Alharbi ${ }^{7}$, \\ Omar O Alsallami ${ }^{7}$, Nagaraja Sreeharsha ${ }^{8,9}$
}

\begin{abstract}
${ }^{1}$ College of Applied Medical Sciences, Shaqra University, Shaqra, SAUDI ARABIA.
${ }^{2}$ Department of Pharmacy Practice, College of Pharmacy, AIMaarefa University, Dariyah, Riyadh, SAUDI ARABIA.

${ }^{3}$ Department of Clinical Laboratory Sciences, The faculty of Applied Medical Sciences, Taif University, Taif, SAUDI ARABIA

${ }^{4}$ Centre of Biomedical Sciences Research (CBSR), Deanship of Scientific Research, Taif University, SAUDI ARABIA.

${ }^{5}$ Clinical Pharmacy Department, King Saud Medical City, Riyadh, SAUDI ARABIA.

${ }^{6}$ Pharmaceutical Services administration, Inpatient Department, King Fahd Medical City, Riyadh, SAUDI ARABIA.

${ }^{7}$ Pharmaceutical Care Services, King Saud Medical City, Riyadh, SAUDI ARABIA.

${ }^{8}$ Department of Pharmaceutical Sciences, College of Clinical Pharmacy, King Faisal University, Al-Hofuf, Al-Ahsa, SAUDI ARABIA.

9Department of Pharmaceutics, Vidya Siri College of Pharmacy, Off Sarjapura Road, Bangalore, Karnataka, INDIA.
\end{abstract}

\begin{abstract}
Background: Anxiety is seen among students even during normal times. The COVID19 pandemic is believed to have increased anxiety and depression among the students. Purpose: An investigation was done to assess the anxiety levels and coping strategies of nursing students in Saudi Arabia. The influence of demographics on the anxiety levels and coping strategies were also determined. Methods: A cross-sectional study was conducted using a questionnaire through Google forms. The questionnaire had items related to demographics such as age, sex, etc., along with a question to know about the confidence of students to work as nurses. A GAD-7 scale was used to assess anxiety levels and BriefCope was used to determine coping strategies. Statistics were performed using non-parametric tests, factorial analysis, and linear regression. Results: More than half of the participating students experienced moderate to severe anxiety. The anxiety levels were not influenced significantly by demographics except the young age. More than $50 \%$ of the students were reluctant to work as nurses and this affected the anxiety score significantly. Factorial analysis grouped variables into six factors. Linear regression showed a positive correlation of these factors with anxiety. Conclusion: Anxiety score revealed that Saudi nursing students had moderate to severe anxiety. The combined number of students reluctant or scared to work was more than those who were confident to work as nurses. A positive association was observed between factor variables with mild and moderate anxiety.
\end{abstract}

Key words: Anxiety, Coping strategy, Factorial analysis, linear regression, Variance, nursing students.

\section{INTRODUCTION}

The frontline healthcare workers; the nurses and the physicians have been strongly affected by the COVID-19 pandemic. ${ }^{1}$ Several hundred doctors and nurses have lost their lives to this pandemic., ${ }^{2,3}$ Though the healthcare profession has never suffered this kind of challenge from any other disease so far, they have shown increased resilience to overcome this challenge. ${ }^{4}$ Several studies have been carried throughout the world to determine the effect of this pandemic on the physical and mental health of the nurses. ${ }^{5,6}$ Though many studies determined the effect of the pandemic on the nurses,
Submission Date: 06-06-2021; Revision Date: 24-07-2021; Accepted Date: 30-09-2021

DOI: 10.5530/ijper.55.3s.170 Correspondence:

Dr. Syed Mohammed Basheeruddin Asdaq, Department of Pharmacy Practice, College of Pharmacy, AlMaarefa University, Dariyah, 13713, Riyadh, SAUDI ARABIA.

Phone: 00966-11-49035553399 ,

Email - sasdag@mcst.edu.sa

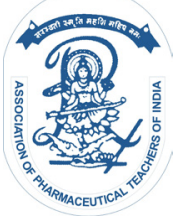

www.ijper.org 
very few studies have determined the psychological impact of this pandemic on the nursing students and their resilience to overcome the challenges.

An earlier study from Israel on the anxiety and coping strategies among nursing students during the COVID-19 pandemic reported moderate to severe anxiety in most of the participants. ${ }^{7}$ Apart from this recent report, there are few earlier reports on the impact of infectious diseases on the anxiety levels of nursing students. During the MERS outbreak in Saudi Arabia, the healthcare students expressed anxiety and reluctance to work due to inadequate protective measures such as infection control and isolation policies. ${ }^{8}$ Similarly, in South Korea, there was reluctance to provide healthcare to patients due to the fear of emerging infections in the future. ${ }^{9}$ Another study during the 2003 SARS outbreak in Hong-Kong reported that nursing students believed that they are at higher risk of infection. ${ }^{10}$ Apart from the fear of working as frontline healthcare workers, the nursing students in some countries have also suffered due to restrictions such as online teaching. A study from Jordan reported several challenges in the successful implementation of online teaching for medical education, ${ }^{11}$ while studies from Saudi Arabia reported successful implementation and acceptability of online mode of teaching among the students. ${ }^{12,13}$

The perception of fear or resilience among the population is largely affected by the infection control measures and restrictions imposed by their governments. ${ }^{14}$ Saudi Arabia is one of the few countries in the world to have successfully controlled the spread of COVID-19 infection through the successful imposition of curfew during the initial COVID-19 outbreak in March 2020 followed by several other measures taken later to prevent the spread of infection. This has led to increased confidence among the people in the kingdom..$^{15,16}$

The objective of the present study was to estimate the anxiety levels of nursing students in Saudi Arabia and the coping strategies adopted by them to overcome the challenges during the COVID-19 pandemic. The fear of working as a nurse and an association of students' characteristics to anxiety levels and coping strategies were also determined.

\section{MATERIALS AND METHODS}

\section{Study Design}

This was a cross-sectional study conducted during the first week of March 2021 among students from different universities in the Riyadh region (Saudi Arabia). Standing Committee for research ethics, Shaqra University,
Saudi Arabia approved the study protocol (ERC_ SU_2021007, dated 17/02/2021).

\section{Characteristics of the participants and methodology}

A total of 109 students participated in this questionnaire-based survey for assessment of anxiety and coping strategies. Most of the participants were students from Colleges of Nursing in Shaqra University (Shaqra) and AlMaarefa University (Riyadh). Students from other universities in Riyadh region that included Princess Nourah Bint Abdulrahman University and King Saud University also participated in the study. The participants were recruited through a snowball sampling technique. A questionnaire prepared using Google forms along with the informed consent was employed to record the responses. There were no specific inclusion and exclusion criteria, any nursing student studying in the nursing department (except first-year students who are freshman students in the four-year nursing course) and willing to participate were included in the study. Brief information about the study was given at the beginning of the questionnaire about the purpose of this study. The informed consent form was shared with the participants electronically along with the questionnaire form. It had several sections that include the purpose of the study, risks, expectation, fees and compensation, options to contact the investigators, and an option to ask for a copy of the questionnaire filled by the student. It was not possible to determine if any student dropped out after opening the forms as responses were recorded only after the students complete the questionnaire and clicked the 'submit button. Furthermore, we did not receive any response in the informed consent, wherein a student clicked that he does not want to participate in the survey. Hence it is considered that all participants of the study consented to participate.

The demographics of students that included age, sex, financial background, number of siblings, employment status, etc., along with fear of working in a hospital were recorded.

The anxiety levels in the students were assessed using The Generalized Anxiety Disorder 7-Item Scale (GAD-7). ${ }^{17}$ This scale has been widely used among adults, adolescents, and college students. ${ }^{18-20}$ An earlier study from Saudi Arabia also suggests that is good for psychometric studies in Saudi male students. ${ }^{21}$ THE GAD-7 questionnaire has seven questions and responses were recorded as not at all (0), several days (1), more than half of the days (2), and nearly every day (3). A cutoff score of 5 shows mild anxiety, a cutoff score 
of 10 indicates moderate anxiety, and a score more than 10 suggests severe anxiety.

For the determination of coping strategies, BriefCOPE, a coping behavior questionnaire designed by Carver et al., was used. ${ }^{22}$ The BriefCOPE questionnaire has twenty-eight questions and the responses were recorded using a Likert scale with a score from 1 to 5; with 1 being strongly disagreed to 5 as strongly agree. Factorial analysis with varimax rotation was done to identify factors with similar variables and Cronbach's alpha was calculated to determine the reliability and consistency of the responses.

\section{Statistical Analysis}

Non-parametric tests- Mann-Whitney and Kruskal Wallis were used to determine the difference in anxiety score. Factorial analysis with varimax rotation was done to identify factors with similar variables. Linear regression was used to determine the association between factors and anxiety.

\section{RESULTS}

\section{Demographics of the student}

As expected, the participating students were young with age ranging from 19 years to 33 years. Both male and female students participated in the study. Most of the participants had more than 5 siblings and their birth order was somewhere in the middle and very few participants were the eldest or the youngest child. The maximum numbers of the participant were from Shaqra University. The number of students undergoing clinical training was more compared to those not taking any clinical training. Most of the participants knew people who had contracted the COVD-19 infection. Many of the student participants believed that their financial status is 'above average' or 'good' and was not working (Table 1). The combined numbers of respondents who recorded that they are scared or'may be' scared to work in the hospital were more than those who were confident of working as nurses (Figure 1).

\section{Anxiety level among the students}

The anxiety levels observed among the students using the GAD-7 scale are shown in Figure 2. The maximum score for a single response is 3 and the maximum total score possible is 21 . The scores were grouped as mild, moderate, or severe anxiety using a cutoff. A cutoff of 5 was used to describe mild anxiety, while a cutoff of 10 was used to indicate moderate anxiety and a score of 15 or more was considered to indicate severe anxiety. Most of the students suffered from moderate anxiety (44\%)

\begin{tabular}{|c|c|c|c|}
\hline Characteristics & $\begin{array}{l}\text { Second } \\
\text { year } \\
\text { students } \\
(n=19)\end{array}$ & $\begin{array}{l}\text { Third year } \\
\text { students } \\
(n=29)\end{array}$ & $\begin{array}{l}\text { Fourth year } \\
\text { students } \\
(n=61)\end{array}$ \\
\hline $\begin{array}{l}\text { Age in Years } \\
\text { (Mean } \pm S D \text { ) }\end{array}$ & $21.33 \pm 2.51$ & $22.36 \pm 3.40$ & $26.46 \pm 3.99$ \\
\hline \multicolumn{4}{|l|}{ Sex } \\
\hline Male & 13 & 14 & 52 \\
\hline Female & 6 & 15 & 9 \\
\hline \multicolumn{4}{|l|}{$\begin{array}{l}\text { Number of } \\
\text { siblings }\end{array}$} \\
\hline$\leq 2$ & 1 & 2 & 5 \\
\hline $3-5$ & 5 & 11 & 26 \\
\hline$\geq 6$ & 13 & 16 & 30 \\
\hline \multicolumn{4}{|l|}{ Birth order } \\
\hline$\leq 2$ & 4 & 13 & 23 \\
\hline $3-5$ & 7 & 9 & 22 \\
\hline$\geq 6$ & 8 & 7 & 16 \\
\hline \multicolumn{4}{|l|}{ University } \\
\hline $\begin{array}{l}\text { Shaqra } \\
\text { University }\end{array}$ & 10 & 14 & 20 \\
\hline $\begin{array}{l}\text { Al-Maarefa } \\
\text { University }\end{array}$ & 5 & 8 & 20 \\
\hline $\begin{array}{c}\text { Other } \\
\text { Universities }\end{array}$ & 4 & 7 & 21 \\
\hline \multicolumn{4}{|l|}{$\begin{array}{c}\text { Presently } \\
\text { undergoing } \\
\text { clinical training }\end{array}$} \\
\hline Yes & 7 & 13 & 30 \\
\hline No & 12 & 16 & 31 \\
\hline \multicolumn{4}{|l|}{$\begin{array}{l}\text { Anyone known } \\
\text { had/have } \\
\text { COVID-19 } \\
\text { infection }\end{array}$} \\
\hline Yes & 5 & 16 & 39 \\
\hline No & 14 & 13 & 22 \\
\hline \multicolumn{4}{|l|}{ Financial status } \\
\hline Not good & 1 & 3 & 2 \\
\hline Average & 7 & 3 & 5 \\
\hline Above average & 5 & 10 & 25 \\
\hline Good & 6 & 7 & 14 \\
\hline Excellent & 0 & 6 & 15 \\
\hline \multicolumn{4}{|l|}{$\begin{array}{c}\text { Occupational } \\
\text { status }\end{array}$} \\
\hline Working & 13 & 4 & 14 \\
\hline Not working & 6 & 25 & 47 \\
\hline
\end{tabular}

followed by severe anxiety (35\%). Mild anxiety was seen in about $30 \%$ of the students.

\section{Influence of demographics on the anxiety scores}

Comparison of anxiety levels according to demographics is shown in Table 2. A significant difference was 


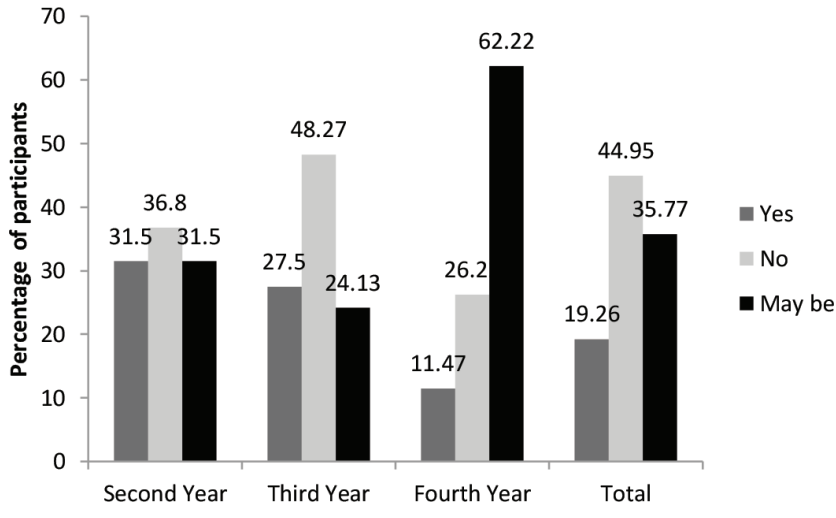

Figure 1: Fear of working in the hospitals (percentage).

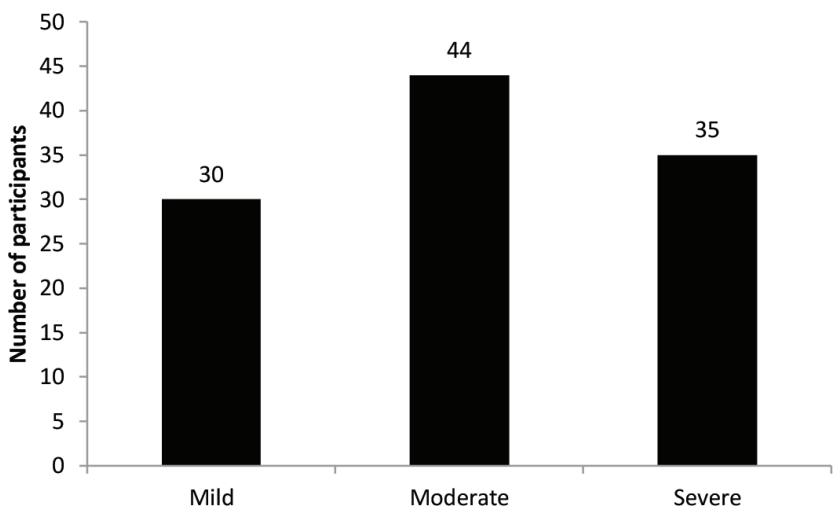

Figure 2: Anxiety levels among the students.

observed in anxiety in different age groups. A post-Dunn test analysis after the Kruskal Wallis test revealed that the anxiety levels in those aged between 21-24 years were significantly less compared to those aged less than 20 years $(P<0.05)$. The anxiety levels were slightly higher in those aged more than 30 years and this difference was not significant. The number of participants who were not scared to work was significantly more compared to those who were scared to work as a nurse $(P<0.05)$ and those who responded 'may be' scared to work as a nurse $(P<0.05)$.

\section{Factor analysis}

The factor analysis was done to reduce items into fewer dimensions. Six components were identified and they contributed together for 58\% of the variability. Factor loadings equal to or greater than 0.5 were selected as the contributing variables (Table 3). Based on the variables, the first factor was referred to as religious coping and it explained $24 \%$ of the variance. The second factor was positive reinterpretation and growth and it accounted for about $9.3 \%$ of the variance. Substance abuse, denial, and use of emotional support were the other factors created through the factorial analysis. The mean score

\begin{tabular}{|c|c|c|}
\hline Characteristics & Mean (SD) & $P$ Value \\
\hline \multicolumn{2}{|c|}{ Age in Years } & \multirow[t]{5}{*}{0.0145} \\
\hline$\leq 20$ years $(n=11)$ & $13.09(3.86)$ & \\
\hline $21-24$ years $(n=83)$ & $8.43(5.14)^{*}$ & \\
\hline $25-29$ years $(n=11)$ & $7.82(3.76)$ & \\
\hline$\geq 30$ years $(n=4)$ & $11.75(8.26)$ & \\
\hline \multicolumn{2}{|l|}{ Sex $(\%)$} & \multirow[t]{3}{*}{0.0917} \\
\hline Male $(n=79)$ & $10.73(5.87)$ & \\
\hline Female $(n=30)$ & $8.29(4.79)$ & \\
\hline \multicolumn{2}{|c|}{ Number of siblings (Mean $\pm S D$ ) } & \multirow[t]{4}{*}{0.0529} \\
\hline$\leq 2(n=8)$ & $6.25(3.01)$ & \\
\hline $3-5(n=42)$ & $10.47(6.01)$ & \\
\hline$\geq 6(n=59)$ & $8.25(4.53)$ & \\
\hline \multicolumn{2}{|l|}{ Birth order } & \multirow[t]{5}{*}{0.063} \\
\hline Only child $(n=2)$ & $12.50(2.12)$ & \\
\hline First child $(n=17)$ & $12.41(6.35)$ & \\
\hline Middle child $(n=77)$ & $8.23(4.72)$ & \\
\hline Youngest $(n=13)$ & $9.46(6.54)$ & \\
\hline \multicolumn{2}{|l|}{ University } & \multirow[t]{2}{*}{0.078} \\
\hline Shaqra University $(n=44)$ & $7.09(3.71)$ & \\
\hline Al-Maarefa University $(n=33)$ & $9.64(4.97)$ & \\
\hline Other universities $(n=32)$ & $9.33(3.86)$ & \\
\hline \multicolumn{2}{|c|}{ Presently undergoing clinical training (\%) } & 0.251 \\
\hline Yes $(n=59)$ & $9.49(5.78)$ & \\
\hline No $(n=50)$ & $8.34(4.39)$ & \\
\hline \multicolumn{2}{|c|}{ Anyone known had/have COVID-19 infection (\%) } & \multirow[t]{3}{*}{0.074} \\
\hline Yes $(n=70)$ & $8.30(4.89)$ & \\
\hline No $(n=39)$ & $10.15(5.54)$ & \\
\hline \multicolumn{2}{|c|}{ Financial status (\%) } & 0.174 \\
\hline Not good $(n=6)$ & $11.83(2.71)$ & \\
\hline Average $(n=15)$ & $9.20(4.19)$ & \\
\hline Above average $(n=40)$ & $9.70(5.46)$ & \\
\hline Good $(n=27)$ & $7.62(4.61)$ & \\
\hline Excellent $(n=21)$ & $8.28(6.29)$ & \\
\hline \multicolumn{2}{|c|}{ Occupational status (\%) } & 0.516 \\
\hline Working $(n=84)$ & $8.78(4.64)$ & \\
\hline Not Working $(n=25)$ & $9.56(6.83)$ & \\
\hline \multicolumn{2}{|c|}{$\begin{array}{l}\text { Scared to work as nurse after COVID-19 } \\
\text { pandemic }(\%)\end{array}$} & 0.0042 \\
\hline Yes $(n=21)$ & $10.95(4.15)$ & \\
\hline No $(n=49)$ & \multirow{2}{*}{$\begin{array}{c}6.81(4.72)^{\#} \\
10.58(5.64)^{+}\end{array}$} & \\
\hline May be $(n=39)$ & & \\
\hline
\end{tabular}

${ }^{*} P<0.05$ compared to $\leq 20$ years in post test, ${ }^{\#} P<0.05$ compared to Yes, ${ }^{+} P<0.05$ compared to No

of the factors is shown in Table 4. Participants scored high in factor 1 (religious coping) followed by factor 5 (Denial). 


\begin{tabular}{|c|c|c|c|c|c|}
\hline $\begin{array}{l}\text { Factor } 1 \text { (Religious } \\
\text { coping) }\end{array}$ & $\begin{array}{l}\text { Factor } 2 \text { (Positive } \\
\text { reinterpretation } \\
\text { and growth) }\end{array}$ & $\begin{array}{c}\text { Factor } 3 \\
\text { (Substance abuse) }\end{array}$ & $\begin{array}{c}\text { Factor } 4 \\
\text { (Acceptance) }\end{array}$ & Factor 5 (Denial) & $\begin{array}{l}\text { Factor } 6 \text { (Use of } \\
\text { emotional social } \\
\text { support) }\end{array}$ \\
\hline $\begin{array}{l}\text { I've been praying or } \\
\text { meditating }(0.816)\end{array}$ & $\begin{array}{c}\text { l've been taking } \\
\text { action to try to make } \\
\text { the situation better. } \\
(0.752)\end{array}$ & $\begin{array}{l}\text { l've been using } \\
\text { alcohol or other } \\
\text { drugs to make } \\
\text { myself feel better. } \\
\quad(0.843)\end{array}$ & $\begin{array}{l}\text { I've been getting } \\
\text { emotional support } \\
\text { from others. }(0.781)\end{array}$ & $\begin{array}{l}\text { I've been refusing } \\
\text { to believe that it has } \\
\text { happened.. }(0.736)\end{array}$ & $\begin{array}{c}\text { I've been getting } \\
\text { help and advice } \\
\text { from other people. } \\
\qquad(0.83)\end{array}$ \\
\hline $\begin{array}{l}\text { I've been giving up } \\
\text { trying to deal with it. } \\
(0.688)\end{array}$ & $\begin{array}{c}\text { I've been } \\
\text { concentrating my } \\
\text { efforts on doing } \\
\text { something about } \\
\text { the situation I'm in. } \\
(0.746)\end{array}$ & $\begin{array}{l}\text { I've been using } \\
\text { alcohol or other } \\
\text { drugs to help me get } \\
\text { through it. }(0.838)\end{array}$ & $\begin{array}{l}\text { I've been accepting } \\
\text { the reality of the fact } \\
\text { that it has happened } \\
\qquad(0.648)\end{array}$ & $\begin{array}{l}\text { I've been saying } \\
\text { things to let my } \\
\text { unpleasant feelings } \\
\text { escape. }(0.617)\end{array}$ & $\begin{array}{l}\text { I've been trying to } \\
\text { get advice or help } \\
\text { from other people } \\
\text { about what to do } \\
(0.79)\end{array}$ \\
\hline $\begin{array}{l}\text { I've been trying to } \\
\text { find comfort in my } \\
\text { religion or spiritual } \\
\text { beliefs. } \\
(0.575)\end{array}$ & & $\begin{array}{c}\text { I've been criticizing } \\
\text { myself } \\
(0.560)\end{array}$ & & $\begin{array}{c}\text { I've been looking for } \\
\text { something good in } \\
\text { what is happening } \\
(0.514)\end{array}$ & \\
\hline \multicolumn{6}{|l|}{$\begin{array}{l}\text { I've been trying } \\
\text { to come up with a } \\
\text { strategy about what } \\
\text { to do }(0.572)\end{array}$} \\
\hline \multicolumn{6}{|l|}{$\begin{array}{c}\text { I've been making } \\
\text { fun of the situation } \\
(0.557) \text {. }\end{array}$} \\
\hline $\begin{array}{c}\% \text { of total variance }= \\
23.99 \%\end{array}$ & $\begin{array}{c}\% \text { of total variance }= \\
9.295 \%\end{array}$ & $\begin{array}{c}\% \text { of total variance }= \\
7.218 \%\end{array}$ & $\begin{array}{c}\% \text { of total variance }= \\
6.38 \%\end{array}$ & $\begin{array}{c}\% \text { of total variance }= \\
5.651 \%\end{array}$ & $\begin{array}{c}\% \text { of total variance }= \\
5.51 \%\end{array}$ \\
\hline $\begin{array}{c}\text { Cronbach's alpha } \\
=0.749\end{array}$ & $\begin{array}{c}\text { Cronbach's alpha } \\
=0.602\end{array}$ & $\begin{array}{c}\text { Cronbach's alpha } \\
=0.742\end{array}$ & $\begin{array}{c}\text { Cronbach's alpha } \\
=0.487\end{array}$ & $\begin{array}{c}\text { Cronbach's alpha } \\
=0.671\end{array}$ & $\begin{array}{c}\text { Cronbach's alpha } \\
=0.735\end{array}$ \\
\hline
\end{tabular}

\begin{tabular}{|c|c|}
\hline $\begin{array}{c}\text { Table 4: Coping strategies score according to factors } \\
\text { after varimax rotation. }\end{array}$ \\
\hline Factors & Mean (SD) \\
\hline Factor 1 (Religious coping) & $11.35(3.46)$ \\
\hline $\begin{array}{c}\text { Factor 2 (Positive } \\
\text { reinterpretation and growth) }\end{array}$ & $5.83(1.89)$ \\
\hline Factor 3 (Substance abuse) & $7.42(2.76)$ \\
\hline Factor 4 (Acceptance) & $5.82(1.91)$ \\
\hline Factor 5 (Denial) & $8.08(2.67)$ \\
\hline $\begin{array}{c}\text { Factor 6 (Use of emotional social } \\
\text { support) }\end{array}$ & $5.50(2.09)$ \\
\hline
\end{tabular}

\section{Linear regression analysis}

The linear regression revealed a significant positive correlation between factor 1 , factor 4 , and factor 6 with mild anxiety and factor 3 with moderate anxiety (Table 5). None of the factors significantly correlated with severe anxiety (Table 5 ).

\section{Coping strategies and demographics}

Analysis of coping strategies using factors obtained from factorial analysis with student demographics did not show any significant relationship (data not shown).

\begin{tabular}{|l|c|c|c|c|c|c|}
\multicolumn{7}{|c|}{ Table 5: Linear regression model for correlation of } \\
extracted factors with anxiety.
\end{tabular}

\section{DISCUSSION}

The present study was done using standard methodology employing the GAD-7 anxiety scale to assess anxiety levels and BriefCOPE to determine coping strategies. The demographic characteristics were carefully selected 
to determine the possible effect of various demographics on the anxiety levels and coping strategies. Despite the fact that the Kingdom of Saudi Arabia had removed many of the COVID-19 restrictions at the time of this report, there is still a fear of infection.

The results revealed that most of the Saudi nursing students experience moderate anxiety followed by students experiencing severe anxiety during this COVID19 pandemic. The anxiety levels were not influenced by demographics except age, wherein a significantly lower anxiety score was observed among students aged between 21-24 years compared to students aged less than 20 years. Factorial analysis revealed six factors that account for $58 \%$ of variables. Religious coping, acceptance, and use of emotional social support have a significant correlation with mild anxiety, and substance abuse has a significant correlation with moderate anxiety, according to linear regression of these factors.

Anxiety is common in general population ${ }^{23}$ especially among students' community even during normal circumstances. The anxiety levels among university students in Hong-Kong before the start of the pandemic showed that about $12 \%$ of students had moderate anxiety and severe anxiety was observed in about $6 \%$ of the students. ${ }^{24}$ In a Portugal study conducted in 2016, about $16 \%$ and $8 \%$ of the students suffered from moderate and severe anxiety, respectively. ${ }^{25}$ Studies on the anxiety levels among students during COVID-19 suggest that this pandemic has affected the mental health of the students. A report from Bangladesh revealed that about $15 \%$ of the students had moderately severe anxiety and $18 \%$ of them suffered from severe anxiety. ${ }^{26}$ In Switzerland, the COVID-19 has impacted the mental health of students more severely, with moderate anxiety in $45 \%$ of students and severe anxiety in about $5 \%$ of the students. ${ }^{27}$ In Turkey, more than half of the students were diagnosed to be suffering from anxiety and depression during this pandemic. ${ }^{28} \mathrm{~A}$ study of international students from a university in Hong-Kong reported adverse effects of COVID-19 on mental health in stayers than returnees. ${ }^{29}$ In Saudi Arabia, a study on the effect of COVID-19 on the mental health of students showed that about $35 \%$ of the students experienced moderate to extreme levels of anxiety that was highly associated with age, sex, and level of education. ${ }^{30} \mathrm{~A}$ study from Israel on the anxiety levels of nursing students reported that mild to moderate levels of anxiety. ${ }^{7}$ The level of anxiety among Saudi nursing students in the present study was similar to that of students of other faculties in Switzerland and Turkey, with more than half of the students reporting moderate to severe anxiety. However, it was different from an earlier report from
Saudi Arabia, ${ }^{30}$ where only 35\% of anxiety was reported among students (non-nursing), which suggests that anxiety levels may differ among students from different specializations. The results also indicate that the profession students pursue may influence the anxiety levels during pandemics as more than half of the students replied that they were either scared or maybe scared to work as nurses.

The GAD-7 scores of 6 to 10 indicate moderate anxiety while a score of more than 15 shows severe anxiety. ${ }^{6}$ As seen from the results, the anxiety levels were moderate in the participants, with most of the demographics showing anxiety scores between 6 to 10 . Age was one of the factors contributing to the anxiety as participants aged less than 20 years showed more anxiety compared to those aged between 21 to 24 years. Though earlier studies have indicated that female healthcare workers are more prone to anxiety compared to their male counterparts, ${ }^{31-33}$ in the present study, no such difference was observed between the male and female students. On the contrary, the anxiety scores were lower in female students than in male students; however, this difference was not significant $(P=0.0917)$.

It is widely believed that siblings help in reducing anxiety and depression. ${ }^{34}$ No significant change was observed in the current study, as most of the participants had siblings except two participants who were the only child of their parents. Similarly, anxiety and depression are less in a firstborn child compared to other children. ${ }^{35}$ Again, very few respondents were the first child of their parents and no significant difference was observed. An attempt to determine if the anxiety levels are different in students studying at various universities did not show any significant difference.

An important finding in this study is the perception of fear among nursing students to work as nurses. About $20 \%$ of the students responded that they have a fear of working in hospitals and this response was similar to students from different academic years. Furthermore, around 35\% could not clearly express their fear, while $45 \%$ of student participants were confident of working as nurses after completing their course. Though the combined number of students reluctant to work as a nurse is more than those who are not scared to work as a nurse, the highest number of participants' response to working as a nurse without fear indicates resilience among undergraduate Saudi nursing students, This result is contrary to an earlier study from Saudi Arabia during the SARS outbreak, which reported that healthcare students were reluctant and anxious to work in hospitals due to lack of protective measures and isolation 
of affected patients. ${ }^{7}$ Students from Hong-Kong and South Korea expressed similar fears. ${ }^{89}$ However, compared to the SARS outbreak, the preventive measures and isolation during the COVID-19 pandemic are more stringent but the COVID-19 is more infectious than the SARS MERS virus. ${ }^{36}$ The students' response to working as nurses reveals confidence in the healthcare system. However, the fear expressed by the students warrants attention from the administration and faculty of the nursing institutions to implement strategies to promote confidence among the nursing students by introducing courses and workshops on infection control.

The BriefCOPE scale is widely used to determine coping strategies and has been validated by several authors. It has 28 items that give information about coping through different strategies, and it is generally agreed that coping strategies are specific to environmental contexts. ${ }^{21}$ In the present study, factorial analysis was used to explore the underlying constructs and identify variables with strong factor loadings. Factorial analysis tells us about the constructs that may exist, though it does not tell us what the constructs are. The factorial analysis gives us groupings that show the items that hold together. Six different factors were identified through factorial analysis with varimax rotation. ${ }^{37}$ The factors were named based on the coping strategies that fall under them.

The first factor that explained 24\% of the variance was referred to as 'religious coping'. With an increase in religious diversion, there was an increase in students' resilience to overcome the challenges. This was expected as Saudi society is strictly religious. Religious education is part of the curriculum starting from school till completion of undergraduate study. Religion is a part of life in the kingdom and the use of verses from religious texts and mentioning the life of religious figures in both private and public life is common. The second factor was termed 'positive reinterpretation and growth' and it explained about 9\% of the variance. An earlier report from Hong Kong about coping strategies among medical students to fight off stress also reported active coping and reinterpretation as the most common strategy. ${ }^{38}$

The third factor, substance abuse, explained about $8 \%$ of the variance. Saudi Arabia is a very conservative country and consumption of substance abuse is a serious criminal offense. Nevertheless, several cases of substance abuse are recorded every year. ${ }^{39}$ The other factors that explained the variance were acceptance, denial, and use of emotional social support. These find- ings are in agreement with an early study from Turkey, where these factors were used to cope with anxiety in male nursing students. ${ }^{40}$

A linear regression of the factors with anxiety showed a positive correlation between the factors and anxiety. Furthermore, the correlation of factor 1 , factor 4 , and factor 6 was significant with mild anxiety while factor 3 was significantly correlated with moderate anxiety. This positive correlation suggests that coping strategies were not effective in reducing the anxiety scores.

As mentioned earlier, the high anxiety scores among students call for measures to promote confidence. Factors contributing to these high levels of anxiety among nursing students should be identified and corrective measures should be taken. Courses/workshops on infection control may help to promote confidence among nursing students. The main limitation of this study is the number of participants. Due to the COVID19 pandemic, it was difficult to reach out to the students from other universities in the kingdom. The best sampling technique under the current circumstances was snowball sampling through students known to teachers. However, this sampling technique could not recruit all the students studying at a university.

\section{CONCLUSION}

The results reveal that more than half of the Saudi nursing students had moderate to severe anxiety. The demographics of the students did not affect the anxiety significantly except the age of the students and fear of working as a nurse. There was no significant influence of demographics on coping strategies. A positive association was observed between factor variables with mild and moderate anxiety.

\section{ACKNOWLEDGEMENT}

The authors are thankful to AlMaarefa University, Riyadh for providing support to do this research.

\section{CONFLICT OF INTEREST}

The authors declare that there is no conflict of interest.

\section{ABBREVIATIONS}

MERS: Middle East Respiratory Syndrome; SARS: Severe Acute Respiratory Syndrome; GAD-7: Generalised Anxiety Disorder Assessment (GAD-7); COVID-19: Coronavirus disease of 2019. 


\section{Funding}

Majid Alhomrani would like to acknowledge TURSP (2020/257).

\section{REFERENCES}

1. Raudenská J, Steinerová V, Javůrková A, Urits I, Kaye AD, Viswanath $O$, et al. Occupational burnout syndrome and post-traumatic stress among healthcare professionals during the novel coronavirus disease 2019 (COVID-19) pandemic. Best Pract Res Clin Anaesthesiol. 2020;34(3):553-60. doi: 10.1016/j.bpa.2020.07.008.

2. Bandyopadhyay $S$, Baticulon RE, Kadhum M, Alser M, Ojuka DK, Badereddin $Y$, et al. Infection and mortality of healthcare workers worldwide from COVID-19: A systematic review. BMJ Glob Health. 2020;5(12):3097. doi: 10.1136/bmjgh-2020-003097, PMID 33277297.

3. Sajad M, Ahmed M, Thakur SC. An outbreak of severe acute respiratory Syndrome-2019 (COVID-19): A major health concern. Indian J Pharm Educ Res. 2020 Oct 1;54(4):847-57. doi: 10.5530/ijper.54.4.177.

4. Albott CS, Wozniak JR, McGlinch BP, Wall MH, Gold BS, Vinogradov S. Battle buddies: rapid deployment of a psychological resilience intervention for health care workers during the COVID-19 pandemic. Anesth Analg. 2020;131(1):43-54. doi: 10.1213/ANE.0000000000004912, PMID 32345861.

5. Talevi D, Socci V, Carai M, Carnaghi G, Faleri S, Trebbi E, et al. Mental health outcomes of the covid-19 pandemic. Riv Psichiatr. 2020;55(3):137-44. doi: 10.1708/3382.33569, PMID 32489190.

6. Shaukat N, Ali DM, Razzak J. Physical and mental health impacts of COVID-19 on healthcare workers: A scoping review. Int J Emerg Med. 2020;13(1):40. doi: 10.1186/s12245-020-00299-5, PMID 32689925.

7. Savitsky B, Findling Y, Ereli A, Hendel T. Anxiety and coping strategies among nursing students during the covid-19 pandemic. Nurse Educ Pract. 2020;46:102809. doi: 10.1016/j.nepr.2020.102809, PMID 32679465.

8. Elrggal ME, Karami NA, Rafea B, Alahmadi L, Al Shehri A, Alamoudi R, et al. Evaluation of preparedness of healthcare student volunteers against Middle East respiratory syndrome coronavirus (MERS-CoV) in Makkah, Saudi Arabia: a cross-sectional study. Z Gesundh Wiss. 2018;26(6):607-12. doi: 10.1007/s10389-018-0917-5, PMID 30533343

9. Oh MD, Park WB, Park SW, Choe PG, Bang JH, Song KH, et al. Middle East respiratory syndrome: what we learned from the 2015 outbreak in the republic of Korea. Korean J Intern Med. 2018;33(2):233-46. doi: 10.3904/ kjim.2018.031, PMID 29506344.

10. Chua SE, Cheung V, Cheung C, McAlonan GM, Wong JWS, Cheung EPT, et al. Psychological effects of the SARS outbreak in Hong Kong on high-risk health care workers. Can J Psychiatry. 2004;49(6):391-3. doi: 10.1177/070674370404900609, PMID 15283534.

11. Al-Balas $\mathrm{M}, \mathrm{Al}$-Balas $\mathrm{HI}$, Jaber $\mathrm{HM}$, Obeidat $\mathrm{K}, \mathrm{Al}$-Balas $\mathrm{H}$, Aborajooh EA, Al-Taher R, Al-Balas B. Distance learning in clinical medical education amid COVID-19 pandemic in Jordan: current situation, challenges, and perspectives. BMC Med Educ. 2020;20(1):341. doi: 10.1186/s12909-02002257-4, PMID 33008392.

12. Khalil R, Mansour AE, Fadda WA, Almisnid K, Aldamegh M, Al-Nafeesah A, et al. The sudden transition to synchronized online learning during the COVID-19 pandemic in Saudi Arabia: A qualitative study exploring medical students' perspectives. BMC Med Educ. 2020;20(1):285. doi: 10.1186/ s12909-020-02208-z, PMID 32859188.

13. Rajab MH, Gazal AM, Alkattan K. Challenges to online medical education during the COVID-19 pandemic. Cureus. 2020;12(7):e8966. doi: 10.7759/ cureus.8966, PMID 32766008.

14. Spoorthy MS, Pratapa SK, Mahant S. Mental health problems faced by healthcare workers due to the COVID-19 pandemic-A review. Asian J Psychiatry. 2020;51:102119. doi: 10.1016/j.ajp.2020.102119, PMID 32339895.

15. Prompt action defines Saudi Arabia's success story. Arab News. Available from: https://www.arabnews.com/node/1721946/prompt-action-defines-saudiarabia's-success-story. [accessed Feb 15 2021].

16. Algaissi AA, Alharbi NK, Hassanain M, Hashem AM. Preparedness and response to COVID-19 in Saudi Arabia: building on MERS experience. J
Infect Public Health. 2020;13(6):834-8. doi: 10.1016/j.jiph.2020.04.016, PMID 32451260.

17. Löwe B, Decker O, Müller S, Brähler E, Schellberg D, Herzog W, et al. Validation and standardization of the generalized anxiety disorder screener (GAD-7) in the general population. Med Care. 2008;46(3):266-74. doi: 10.1097/MLR.0b013e318160d093, PMID 18388841.

18. Mossman SA, Luft MJ, Schroeder HK, Varney ST, Fleck DE, Barzman DH, et al. The generalized Anxiety Disorder 7-item scale in adolescents with generalized anxiety disorder: Signal detection and validation. Ann Clin Psychiatry. 2017;29(227). /pmc/articles/PMC5765270/.

19. Byrd-Bredbenner C, Eck K, Quick V. Psychometric properties of the generalized anxiety Disorder-7 and generalized anxiety disorder-mini in United States university students. Front Psychol. 2020;11:550533. doi: 10.3389/fpsyg.2020.550533.

20. Lee B, Kim YE. The psychometric properties of the Generalized Anxiety Disorder scale (GAD-7) among Korean university students. Psychiatry Clin Psychopharmacol. 2019;29(4):864-71. doi: 10.1080/ 24750573.2019.1691320.

21. Alghadir A, Manzar MD, Anwer S, Albougami A, Salahuddin M. Psychometric properties of the generalized anxiety disorder scale among Saudi university male students. Neuropsychiatr Dis Treat. 2020;16:1427-32. doi: 10.2147/ NDT.S246526, PMID 32606696.

22. Carver CS, Scheier MF, Weintraub JK. Assessing coping strategies: A theoretically based approach. J Pers Soc Psychol. 1989;56(2):267-83. doi: 10.1037//0022-3514.56.2.267, PMID 2926629.

23. Singh D, Prusty SK, Sarangi SS, Sahoo S, Biswal AK. Attitude, anxiety, psychological effects and prevention during COVID-19 in India. Indian J Pharm Educ Res. 2020;54(3s):s400-10. doi: 10.5530/ijper.54.3s.138.

24. Lun KWC, Chan CK, Ip PKY, Ma SYK, Tsai WW, Wong CS, et al. Depression and anxiety among university students in Hong Kong. Hong Kong Med J. 2018;24(5):466-72. doi: 10.12809/hkmj176915, PMID 30245480.

25. Bártolo A, Monteiro S, Pereira A. Factor structure and construct validity of the Generalized Anxiety Disorder 7-item (GAD-7) among Portuguese college students. Cad Saude Publica. 2017;33(9):e00212716. doi: 10.1590/0102311X00212716, PMID 28977285

26. Islam MA, Barna SD, Raihan H, Khan MNA, Hossain MT. Depression and anxiety among university students during the COVID-19 pandemic in Bangladesh: A web-based cross-sectional survey. PLOS ONE. 2020;15(8); Aug 15-8:e0238162. doi: 10.1371/journal.pone.0238162, PMID 32845928.

27. Dratva J, Zysset A, Schlatter N, von Wyl A, Huber M, Volken T. Swiss university students' risk perception and general anxiety during the covid-19 pandemic. Int J Environ Res Public Health. 2020;17(20):1-11. doi: 10.3390/ ijerph17207433, PMID 33066008.

28. Aslan I, Ochnik D, Çınar O. Exploring perceived stress among students in Turkey during the covid-19 pandemic. Int J Environ Res Public Health. 2020;17(23):1-17. doi: 10.3390/ijerph17238961, PMID 33276520.

29. Lai AY, Lee L, Wang MP, Feng Y, Lai TT, Ho LM, Lam VS, Ip MS, Lam TH. Mental health impacts of the COVID-19 pandemic on international university students, related stressors, and coping strategies. Front Psychiatry. 2020;11:584240. doi: 10.3389/fpsyt.2020.584240.

30. Khoshaim HB, Al-Sukayt A, Chinna K, Nurunnabi M, Sundarasen S, Kamaludin K, Baloch GM, Hossain SFA. Anxiety level of university students during COVID-19 in Saudi Arabia. Front Psychiatry. 2020;11:579750. doi: 10.3389/fpsyt.2020.579750.

31. Li G, Miao J, Wang H, Xu S, Sun W, Fan Y, Zhang C, Zhu S, Zhu Z, Wang W. Psychological impact on women health workers involved in COVID-19 outbreak in Wuhan: A cross-sectional study. J Neurol Neurosurg Psychiatry. 2020;91(8):895-7. doi: 10.1136/jnnp-2020-323134, PMID 32366684.

32. AlAteeq DA, Aljhani S, Althiyabi I, Majzoub S. Mental health among healthcare providers during coronavirus disease (COVID-19) outbreak in Saudi Arabia. J Infect Public Health. 2020 Oct;13(10):1432-1437. doi: 10.1016/j.jiph.2020.08.013. Epub 2020 Sep 10. PMID: 32933881; PMCID: PMC7834809.

33. Hou F, Bi F, Jiao R, Luo D, Song K. Gender differences of depression and anxiety among social media users during the COVID-19 outbreak in China:a cross-sectional study. BMC Public Health. 2020;20(1):1648. doi: 10.1186/ s12889-020-09738-7, PMID 33148202. 
34. What about me? Siblings of children with an anxiety disorder on JSTOR [cited Feb 16 2021]. Available from: https://www.jstor.org/stable/42659627?seq=1.

35. Hardt J. Anxiety and depression as an effect of birth order or being an only child: results of an internet survey in Poland and Germany. Insights Depress Anxiety. 2017;1(1):015-22. doi: 10.29328/journal.hda.1001003.

36. Hu T, Liu Y, Zhao M, Zhuang Q, Xu L, He Q. A comparison of COVID-19, SARS and MERS. PeerJ. 2020;8:e9725. doi: 10.7717/peerj.9725, PMID 32879801.

37. Factor Analysis - an overview | ScienceDirect Topics [cited Feb 16 2021]. Available from: https://www.sciencedirect.com/topics/psychology/factoranalysis.
38. Stewart SM, Betson C, Lam TH, Marshall IB, Lee PWH, Wong CM. Predicting stress in first year medical students: A longitudinal study. Med Educ. 1997;31(3):163-8. doi: 10.1111/j.1365-2923.1997.tb02560.x, PMID 9231132.

39. Almarhabi $\mathrm{Y}$, Mufti Al, Almaymuni AD, Abdurahman T, Abdulaziz G, Alghamdi AA, Moniem Mukhtar A. Substance abuse at early age as a potential risk factor for driving under the influence of substance in Jeddah, Saudi Arabia: A cross-sectional study. Traffic Inj Prev. 2018;19(7):687-92. doi: 10.1080/15389588.2018.1494828, PMID 30040504.

40. Turan N, Özdemir Aydın G, Kaya H, Aksel G, Yılmaz A. Male nursing students' social appearance anxiety and their coping attitudes. Am J Mens Health. 2019;13(1):1557988319825922. doi: 10.1177/1557988319825922, PMID 30739556.

Cite this article: Asad M, Alenezi AK, Alsalowly MN, Asdaq SMB, Alamri AS, Alsanie WF, et al. Self-reported Anxiety and Coping: A Cross-Sectional Study among Saudi Nursing Students during COVID-19 Pandemic using Gad-7 and Briefcope. Indian J of Pharmaceutical Education and Research. 2021;55(3s):s637-s645. 